\title{
MATRICIAMENTO EM SAÚDE MENTAL EM UM MUNICÍPIO DE MÉDIO PORTE
}

\author{
Tássia Mayra Oliveira Farias* \\ Henrique Figueiredo Carneiro*
}

RESUMO: 0 presente artigo tem por objetivo investigar a dinâmica de implantação de matriciamento em saúde mental em um município de médio porte, considerando os fatores facilitadores, bem como suas dificuldades. A pesquisa trata-se de um estudo de campo exploratório e qualitativo, realizado por meio de entrevistas semiestruturadas, que contou com a participação de seis profissionais coordenadores de instituições ligadas à prática de matriciamento em saúde mental. A análise do material seguiu por meio de categorização, subdividida em cinco critérios, que representam: as dificuldades para o matriciamento; as ações favoráveis ao matriciamento; o planejamento matricial e 0 acompanhamento profissional; o matriciamento na relação entre a Atenção Básica e o serviço de saúde mental; e o sentido de matriciamento para os profissionais. É possível concluir que o município necessita de intervenções voltadas à formação profissional e pessoal dos profissionais, em que inclusive, 0 psicólogo pode contribuir de forma significativa.

PALAVRAS-CHAVE: Matriciamento; Saúde Mental, Atenção Básica; CAPS.

\section{THE MATRIXING PROCESS IN MENTAL HEALTH IN A MEDIUM-SIZED TOWN}

\begin{abstract}
The dynamics of matrixing implantation in mental health in a medium-sized town are investigated, in which the facilitating factors and the difficulties are taken into consideration. An exploratory and qualitative field study was undertaken by half-structured interviews with six coordinating professionals of institutions featuring matrixing in mental health. Material was analyzed by categorization, subdivided into five criteria, demonstrating difficulties for matrixing, favorable activities to matrixing, matrixal planning and professional follow-up, matrixing between Basic Care and the mental health service, and the significance of matrixing for professionals. Results show that the town requires interventions in professional and personal formation of specialized personnel in which the psychologist has specific contributions.
\end{abstract}

KEYWORDS: Matrixing; Mental health, Basic Care; CAPS.

\section{INTRODUÇÃO}

0 matriciamento em saúde mental é uma proposta que atrela atividades de cuidado colaborativo da Estratégia de Saúde da Família (ESF), com o Centro de Atenção Psicossocial (CAPS), em conformidade de coresponsabilização e cogestão entre as equipes. Podendo ser entendido como "um novo modo de produzir saúde em que duas ou mais equipes, num processo de construção compartilhada, criam uma proposta de intervenção pedagógico-terapêutica"
(BRASIL, 2011, p. 13). Desta forma, a ESF assume 0 papel de equipe de referência e os especialistas do CAPS de equipe de apoio matricial para a produção dos cuidados na saúde mental.

No processo de matriciamento, as equipes de referência tem como responsabilidade 0 acompanhamento longitudinal dos usuários, pelo fato de estarem inseridas no contexto da comunidade e atuarem na formação de vínculos. 0 vínculo caracteriza-se como agente potencializador das ações em saúde, e auxilia no aumento da resolubilidade de

\footnotetext{
Psicóloga pela Universidade de Pernambuco (UPE), Campus Garanhuns (PE), Brasil; E-mail: tassiamayra@outlook.com

* Doutorado em Psicologia pela Universidad Pontificia Comillas Madrid; Docente Adjunto da Universidade de Pernambuco (UPE); Coordenador do Mestrado Saúde Mental Universidade de Pernambuco (UPE), Campus Garanhuns (PE), Brasil.
} 
ações da ESF. A equipe de apoio matricial, por sua vez, visa "oferecer tanto retaguarda assistencial quanto suporte técnico pedagógico às equipes de referência". (CAMPOS; DOMITTI, 2007, p. 400). Desta forma, a equipe de apoio matricial pode lidar diretamente com os usuários do serviço, ou apenas com os profissionais da ESF, por meio dos auxílios técnicos pedagógicos.

A ação matricial tem por finalidade diminuir o sistema excessivo de encaminhamentos ao serviço de especialidade, que está culturalmente arraigado, e amenizar os efeitos da institucionalização ao propor um cuidado territorializado, que não destitui o sujeito de seu lugar social. Nicácio e Campos (2004) sugerem atenção com esta ação pela necessidade da interação entre profissionais, usuários, familiares e instituição, pois a prática territorial se constrói à medida que há interatividade entre os envolvidos. Revelando-se não apenas na mudança de um lócus, mas na complexidade da ação concreta em romper 0 fazer instituído e 0 fazer técnico. Assim, não basta transpor uma equipe profissional para a comunidade, pois a mudança antes de tudo deve acontecer diariamente nas práticas, e estas serem ampliadas (CARNEIR0, 2014).

Nesta conformidade que 0 matriciamento torna-se uma estratégia de grande importância, podendo ser enriquecido com a psicologia, pois traça uma linha de pensamento que desloca o foco na intervenção, da doença para o sujeito, acreditando que, assim, haverá maior produção de saúde. Uma vez que considera 0 indivíduo em suas particularidades, sendo a patologia apenas uma delas. Inspirado na concepção basagliana, Campos (2003) propõe uma ideia de clínica, em que o sujeito e sua história não são reduzidos à doença, como na proposição da medicina positivista, mas que também não coloca a doença em parênteses, enquanto ela está ali todo 0 momento denunciando sua presença. Incitando assim a construção de uma clínica que se utiliza dessa retirada de foco da doença, como uma via de acesso ao sujeito, sujeito esse, inclusive, que está em sofrimento.

A psicologia apresenta sua contribuição para 0 matriciamento, à medida que é respaldada justamente por diretrizes que consideram primordialmente 0 sujeito em sofrimento, e oferece um olhar para a subjetividade dele. Outro aspecto importante da atuação do psicólogo no matriciamento trata-se da escuta. Segundo Pietroluongo e Resende (2007, p. 29), a escuta psicológica tem capacidade de "proporcionar momentos de subjetivação do sistema familiar, favorecendo a ampliação da percepção da equipe e da própria família acerca dos problemas suscitados", promovendo assim uma prática que não está embasada na objetificação de uma demanda.

Os conceitos e as práticas psicológicas contribuem a gestão do apoio matricial, uma vez que, conforme Santos (2014), a dicotomização do processo saúde-doença colabora para perpetuação de um modelo hospitalocêntrico, verticalizado, e departamentalizado. No entanto, a prática de matriciamento inverte essa lógica de organização e explícita a necessidade de uma gestão que se organize de forma transversal, com vistas a realizar um modo de trabalho interativo, em que a disputa de poder entre os profissionais e suas áreas de saber, possa dar lugar à construção de sentidos e intervenções que cada vez mais possuam condições de abarcar a complexidade que o fenômeno em saúde incita. Conforme Pedroso e Vieira (2009), esta transversalidade no cuidado direciona-se ao diálogo e à problematização acerca dos diferentes saberes e suas fronteiras. 0 apoio matricial propõe um modelo de cogestão, ou seja, de gestão compartilhada, que sugere transdisciplinaridade no fazer, auxiliada pela psicologia no reconhecimento dos sujeitos envolvidos e no estreitamento do vínculo.

Segundo Luzio e L'Abbate (2009), no que concerne à assistência à saúde mental, os municípios de pequeno e médio portes, por meio do Sistema Único de Saúde (SUS), incluíram Unidades de Saúde da Família (USF), entretanto, isso não representa necessariamente a execução de projetos em saúde mental respaldados pela proposta da reforma psiquiátrica. Em grande parte da demanda de saúde mental nos municípios de médio porte, é assistida mediante à internação psiquiátrica e a utilização de terapêuticas medicamentosas. Havendo um retrocesso 
nas práticas, que acabam por reproduzir o modelo da psiquiatria hegemônica.

Campos e Domitti (2007) demonstram que 0 matriciamento confronta com limitações de diversas naturezas, como barreiras estruturais, que diz sobre um modo excessivamente departamentalizado de se operar nas organizações; político comunicativas, que se refere à pouca comunicação que existe entre setores e profissionais, e a centralização de poder verificada em determinados cargos; impedimentos subjetivos e culturais, que fala de uma abertura pessoal necessária para construção de um fazer compartilhado, que anule concorrências; barreiras epistemológicas, pois cada núcleo de saber tende a manter-se restrito em seu conhecimento e as éticas, que discorrem sobre a dificuldade de lidar com 0 sigilo dentro de uma equipe multiprofissional.

Neste incurso, este estudo trata-se de averiguar quais obstáculos um município de médio porte, do Estado de Pernambuco, enfrenta para a realização do matriciamento em saúde mental. Tendo como objetivo a investigação da dinâmica de implantação de matriciamento em saúde mental no município, considerando os fatores facilitadores, e dificuldadores do processo.

\section{METODOLOGIA}

Esta pesquisa é de natureza qualitativa, e caracteriza-se como um estudo de campo exploratório, uma vez que perpassado por interpretações, buscou junto à gestão, que está envolvida com a saúde mental, a construção de um sentido para os obstáculos que o município de Garanhuns-PE confronta-se para a implantação o do matriciamento.

Mediante uma breve exploração no contexto do município de Garanhuns-PE é possível observar que este detém um quantitativo populacional de médio porte, dispondo de diversos aparelhos de saúde alternativos aos manicômios, como NASF (Núcleo de Atenção à Saúde da Família), CAPS II (sofrimento mental), CAPS ad (Álcool e outras drogas) e Residência
Terapêutica. Entretanto, percebe-se dificuldade para a atuação do CAPS em território, e no que concerne ao acolhimento realizado nas Estratégias de Saúde da Família (ESF) para a demanda de saúde mental, este baseia-se na distribuição de medicação (geralmente entregue a familiares) ou encaminhamento para 0 médico especialista.

A coleta de dados somente ocorreu após aprovação do Comitê de Ética da Universidade de Pernambuco-UPE, sob o parecer número 1226890, na data 14 de setembro de 2015 . No que diz respeito aos critérios de inclusão e exclusão, foram convidados indivíduos que estão envolvidos em coordenadorias dos dispositivos ligados à prática matriciadora em saúde mental, sendo eles o CAPS-ad, CAPS ॥ e coordenadores geral da Atenção Básica. Estes profissionais participaram segundo seu interesse em contribuir com 0 estudo. A preferência por coordenadores em detrimento de outros funcionários, justifica-se pelo recorte sob viés da gestão que a pesquisa se propõe a realizar, fato que excluiu outros profissionais do estudo. Diante destes critérios, 0 resultado foi a participação de seis coordenadores envolvidos na rede de atenção à saúde primária $\mathrm{e}$ secundária.

Como instrumento para a coleta de dados, foi utilizada a entrevista semi-estruturada. 0 roteiro da entrevista foi composto por dez perguntas abertas, as quais de modo geral versavam sobre aspectos que envolvem a prática de matriciamento. As perguntas foram elaboradas e para isto foi realizada uma aproximação com o campo de estudo, mediante diálogos informais com funcionários de algumas ESF's, que proporcionaram a contextualização da entrevista com a realidade local.

0 procedimento de coleta de dados transcorreu-se da seguinte forma: as cartas de anuência e concessão foram assinadas pela Secretária de Saúde de Garanhuns-PE, com isso a pesquisa pode seguir de modo que todos os participantes foram contatados e entrevistados em seus próprios lugares de trabalho. Os envolvidos na pesquisa assinaram o Termo de Consentimento Livre e EsclarecidoTCLE, tal documento coloca 0 sujeito em posição de 
conhecimento acerca de tudo aquilo que se pretende desenvolver e assegura-0s, pela Resolução CNS $n^{0}$ 466/2012, total assistência em momentos que estes a demandem. 0 TCLE ainda possibilita posteriores contatos, caso assim seja necessária a pesquisa. É válido salientar que a identidade dos profissionais participantes da pesquisa foram preservadas mediante nomes fictícios, os quais foram criados fora de qualquer associação ao seu nome real, para garantir os preceitos da resolução CNS. Em seguida foram realizadas as entrevistas de forma individual, elas foram gravadas, mediante a permissão do participante, e posteriormente transcritas de forma íntegra, como forma de manter fidelidade aos dados coletados.

Os dados foram analisados por meio da Análise de Conteúdo Categorial (BARDIN, 2006), a qual sugere a construção de categorias de análise, classificadas em: dificuldades para 0 matriciamento; ações favoráveis ao matriciamento; planejamento matricial e 0 acompanhamento profissional; matriciamento na relação entre a Atenção Básica e o serviço de saúde mental; e sentido de matriciamento.

A interpretação dos dados categorizados sucedeu diante das semelhanças nas falas dos entrevistados, havendo uma descrição dos conteúdos encontrados, e posteriores articulações com aquilo ofertado pela literatura pertinente.

\section{RESULTADOS E DISCUSSÕES}

Com a apreciação dos dados na categorização, apresentaram-se fatores que representam obstáculos e potencialidades à implantação de matriciamento no município e, por conseguinte, respaldaram a construção das categorias supracitadas. Vale ressaltar que 0 município não possui uma equipe que se responsabilize pela coordenação de saúde mental.

\subsection{AS DIFICULDADES PARA MATRICIAMENTO}

Mediante as falas que evidenciam os obstáculos que dificultam 0 matriciamento, as principais limitações ressaltadas pelos profissionais foram: o modelo de atendimento, a prática acolhedora, a gestão financeira e a rotatividade de pessoal.

0 modelo biomédico ainda incutido no cuidado, a tendência de enfatizar a busca da cura, e a remissão de sintomas como o sucesso de uma terapêutica, ainda está muito presente no contexto atual da saúde. Este forma de cuidado que se faz ativa, se evidencia na fala:

Eu acho que o maior desafio [...] é a mudança na cultura [...] as vezes essas ações são burladas por essa cultura mesmo, que a gente tem de curativista. (Jorge-Atenção Básica).

Ao pontuar sobre 0 modelo hegemônico da clínica, Cunha (2004, p. 19) expressa que "a clínica médica tradicional tem uma tendência a se responsabilizar somente pela enfermidade e não pelo sujeito doente, o que significa que existem ainda grandes dificuldades para a efetiva transformação da clínica no SUS". Esse obstáculo pode ser entendido como vestígios de uma psiquiatria dominante do século XIX, que se configurou como um saber de grande influência sobre os sujeitos, seguindo um caminho de natureza positivista, reforçando cada vez mais preceitos das ciências naturais e direcionando a sua ação para a construção de diagnósticos e busca de cura (AMARANTE, 1995).

A contribuição da psicologia em práticas de saúde mental direciona-se a produção de subjetividade em saúde, como forma de produzir cortes na cultura tradicional de intervenção, que se baseia na lógica de causa e efeito, voltando-se assim para recriar e questionar as práticas vigentes, por meio da aproximação com os aspectos de natureza psicossocial de determinada demanda (DIMENSTEIN; MACED0, 2012).

A tradição de uma medicina das evidências acabou por colocar o fazer do médico em uma posição de supremacia em detrimento a outras áreas de saber, pois conforme Melo et al. (2014, p. 496) "o Brasil possui como característica marcante a predominância 
da assistência médica curativa e individual". Movimentos como a Reforma Sanitária e Psiquiátrica, especificamente no caso da saúde mental, promoveram práticas alternativas do cuidado, pois como menciona Dias (2007, p. 54) "0 significado inovador do movimento da reforma sanitária foi sua proposta de ruptura com a forma histórica de constituição da política de saúde no Brasil: centralizadora, autoritária, privativista, hospitalocêntrica, meritocrática e residual". Porém, verificam-se atuações rotineiras resistentes a este novo fazer. A fala de Otávio (Atenção Básica) evidencia essa incorporação:

Então acho que a maior dificuldade realmente é o profissional, não ter a sensibilização do que é esse trabalho né?

Tendo em vista a fala citada, é possível ressaltar que há políticas públicas de saúde que preconizam a descentralização do poder de resolutividade do médico, e estimulam estratégias voltadas para 0 cuidado mais amplo e humanizado, observado, por exemplo, em políticas que colocam aspectos como lazer, trabalho, atividade física e educação, como determinantes para saúde (LEI nº 8.080, 1990). Entretanto uma dificuldade para que estas ações possam de fato ser colocadas em prática, diz respeito à sensibilização dos profissionais em ocupar este novo lugar, e pensar a saúde de forma multidimensional, em todo o contexto de saúde e não apenas no consultório restrito.

Expandir a prática além do modelo médico e de consultório, estabelece uma ação direta com 0 acolhimento. Tendo em vista que a concepção de acolhimento envolve um acompanhamento Iongitudinal, processual, e de constante análise. 0 que está sendo desenvolvido na ESF do Município ainda consiste em um atendimento pontual, que muitas vezes se reduz a um trabalho de recepção, 0 que dificulta a prática, como evidenciado:

0 acolhimento ele acontece, mas não é ainda da forma ideal [...] Ele tem se configurado da seguinte maneira, existe os profissionais que diariamente são designados para acolher esse usuário. Mas assim, a forma como isso é feito, uma forma como deve ser feita, porque deve ser feita, qual sentido disso é que deve ser trabalhado. (Jorge-Atenção Básica)

Mas 0 acolhimento ele é realizado na recepção né, onde o paciente vai abordar né, vai dizer as suas queixas e 0 que é que ele procura, e depois ele vai ser direcionado pra determinado serviço, como atendimento pra enfermeira, atendimento da médica, se for uma vacina, se for 0 curativo. (Talita-Atenção Básica).

Diante disto, vale salientar a diferença existente entre 0 que se entende por acesso e por acolhimento. Uma vez que 0 acesso, trata-se daquilo que é realizado durante a entrada ao serviço, enquanto que 0 acolhimento em si remete à construção de vínculos, que visa estimular a autonomia e cidadania do usuário. A construção do vínculo depende de diversas variáveis e só pode acontecer à medida que 0 indivíduo é reconhecido enquanto sujeito desejante, capaz de participar e arbitrar na produção de saúde (SCHIMITH; LIMA, 2004).

De acordo com Matumoto (1998), 0 acolhimento não pode ser entendido apenas como um atendimento em recepção, mas deve concentrar-se também em uma responsabilização no que concerne à demanda do usuário, caracterizando-se assim como um processo que perdura por todo atendimento $\mathrm{e}$ intervenções na produção de saúde. Sendo assim, no matriciamento as práticas acolhedoras favorecem a dinâmica do serviço e auxilia a triagem em relação à prática de cuidado.

Os recursos financeiros se tornam um dificultador da prática matricial, os quais acabam por ser deficientes, conforme relatado pelos profissionais. A exemplo estão as falas de Ricardo e Raquel respectivamente, quando questionados acerca dos obstáculos para realização de matriciamento:

Eu acho que é mais a parte de recurso financeiro. (Ricardo-CAPS-ad)

0 maior desafio rapaz, um é, eu vou te dizer que seria o financeiro também. (Raquel- CAPS II) 
Diante desta situação de escassos recursos relatada nas falas anteriores, vale ressaltar que 0 art. $1^{0}$ da portaria $n^{0}-3.089$, de 23 de dezembro de 2011, institui 0 "repasse financeiro fixo para os centros de atenção psicossocial (CAPS) credenciados pelo ministério da saúde, destinado ao custeio das ações de atenção psicossocial realizadas". Entretanto, este incentivo financeiro ainda é insuficiente e acaba por interferir no bom funcionamento do serviço, pois como Campos e Domitti (2007) afirmam, a carência de recursos trata-se de um dos obstáculos ao apoio matricial, uma vez que a proporção da quantidade de serviços para as demandas ainda é insuficiente, e que os recursos existentes precisam ser utilizados de formas mais adequadas.

A rotatividade dos profissionais é uma dificuldade para o matriciamento, uma vez que os profissionais que estão envolvidos necessitam de capacitação constante, de aprimoramento para trabalhar segundo a recomendação do SUS e da Reforma Psiquiátrica. Com a mudança constante, as capacitações passam a ser adaptadas, foge do aprimoramento específico e passa a ser a repetição inicial do serviço. As falas de Regina e Raquel, respectivamente, expressam esta deficiência:

\footnotetext{
Eu acredito que as equipes, a gente assim as vezes tem um fluxo muito grande de rotatividade desses profissionais. (Regina-Atenção Básica)

Porque tem mudança de muitos profissionais, a rotatividade é grande. (Raquel-CAPS II)
}

Este fato expressa a necessidade de uma educação permanente atuante e voltada também para a saúde mental. Educação permanente pode ser entendida como "um processo educativo contínuo, [...] com objetivo de qualificação, reafirmação ou reformulação de valores, construindo relações integradoras entre os sujeitos envolvidos para uma praxe crítica e criadora" (TAVARES, 2006, p. 288). Destarte, no campo específico da saúde mental, a educação permanente busca reafirmar os pressupostos da reforma psiquiátrica, para trabalhar a construção de novas práticas, as quais devem também estar embasadas nas diretrizes do SUS.

\subsection{AS AÇÕES FAVORÁVEIS AO MATRICIAMENTO}

Em função das falas coletadas nas entrevistas, foi possível observar ações favoráveis à implantação do matriciamento, das quais se pode destacar a comunicação entre CAPS e Atenção Básica, a intersetorialidade e o mapeamento do município.

0 discurso dos profissionais evidencia que a comunicação entre os CAPS's e a Atenção Básica acontece por meio de reuniões e seminários. Como demonstra a fala:

Por exemplo, uma reunião nossa
mesmo ocorreu há dois meses
atrás [...] CAPS e Atenção Bási-
ca, porém, no mês de setembro
a gente já iniciou um trabalho
de reuniões frequentes, assim já
marcada de uma a duas vezes.
(Otávio-Atenção Básica)

A comunicação entre a Unidade de Saúde da Família (USF) e o serviço de saúde mental é de extrema importância para que uma rede de cuidado em saúde mental possa tecer caminhos de integralidade em sua assistência, e no contexto do município esta abertura para diálogo pode ser vista como um fator de potencial à atividade matricial. A proposta de atenção integral envolve um trabalho que se inicia nas USF's, considerando que estas são a porta de entrada para 0 serviço em saúde, e caminha em sentido de atuações multiprofissionais, que ofereçam diversas dimensões daquela demanda.

Neste sentido, Ayres (2001) traz a proposta de um diálogo, que vai além da união de técnicas, mas que está atravessada por uma dimensão intersubjetiva, que exige 0 reconhecimento e aceitação do outro enquanto um sujeito de desejo. Para Santana et al. (2010, p. 1654), esse "encontro desejante com 0 outro implica mudanças nas relações de poder, entre os profissionais de saúde e os usuários. É nesse processo 
dia-lético e dinâmico que poderemos garantir práticas inovadoras" havendo assim um sentido mais amplo daquilo que a integralidade envolve.

As atividades voltadas para a intersetorialidade pode ser evidenciada no relato dos entrevistados. Uma vez que existem afirmações de trabalhos articulados à educação, à promotoria pública e aos setores sociais, como 0 Centro de Referência de Assistência Social (CRAS) e o Centro de Referência Especializado de Assistência Social (CREAS). A fala a seguir referencia essa articulação da saúde com a educação.

Nas escolas a gente percebe muito
a necessidade de ações em saúde
mental, e são trazidas inclusive,
pelas gestoras da educação [...] e
a gente tem um grupo de traba-
lho chamado GTI, esse GTI propõe
ações também, de forma interse-
torial, no sentido da saúde mental.
Esse grupo de trabalho em saúde
mental, é colocado também nas
escolas pra que os profissionais
possam lidar com as situações.
(Jorge-Atenção Básica)

Vale salientar a importância de voltar um olhar à forma como se dá esta comunicação, neste processo intersetorial, para que a mesma realmente possa acontecer de forma dinâmica e eficaz, e que não seja reduzida a processos burocráticos, os quais inclusive, o SUS tem combatido. A comunicação entre os serviços possibilita "uma rede de interdependência e corresponsabilização entre os equipamentos na direção da garantia do atendimento integral, materializando, assim, 0 conceito de trabalho em rede" (FERRO et al. 2014, p.131). Logo, a efetiva comunicação intersetorial produz uma prática pautada na interdisciplinaridade e integralidade, que é crucial para o matriciamento em saúde mental, e que reafirma a ética com a promoção de saúde.

Os achados nas entrevistas apontam como principal via de acesso intersetorial os encaminhamentos, os quais têm por finalidade promover a interação entre instituições para proporcionar ao usuário um atendimento mais amplo e estruturado, que cada vez mais possa dar conta de sua demanda. Como expressado na fala de Raquel (CAPS II):
Na comunidade nós trabalhamos em rede, trabalhamos com Aten- ção Básica, nós trabalhamos com CRAS, com CREAS, NASF, nós tra- balhamos com Promotoria Pública [...] Esse trabalho ele é feito em equipe, encaminhamentos.

A prática de encaminhamentos é primordial para garantir 0 cuidado àquele que está em sofrimento mental, à medida que envolve diversas instituições na assistência ao usuário e fortalece 0 matriciamento. Entretanto,vale salientarque estaatuação exige cautela, para que não se transforme em formas de atuação desarticulas que "reflete um modelo burocrático de gestão das políticas públicas de caráter hierarquizado e centralizador, e que contribuem para práticas que não geram a promoção humana" (RABELO, 2015). Assim, a prática intersetorial configura-se como um desafio, pois exige dos dispositivos uma estratégia de movimentação, para que de fato as instituições possam estar articuladas entre si, de forma que venha promover saúde.

0 mapeamento do município é primordial na prática matricial, pois identifica as áreas de vulnerabilidade, observando suas demandas, para que as intervenções possam ser planejadas, incluídas e redistribuídas. Esta ação favorável fica evidenciada pela fala de Talita (Atenção Básica):

É, a residência junto com a gente, a Atenção Básica [...] eles tão vendo tanto a necessidade do matriciamento dos CAPS's, como também nos NASF's. [...] estão remapeando, certo... porque a população de Garanhuns, ela cresceu [...] então a quantidade de população pra as unidades estão sobrecarregadas.

A identificação de novas áreas do município e a aproximação com seus respectivos contextos são de grande relevância e podem ser entendidos como atividade de potencial para 0 matriciamento. Cada território possui suas peculiaridades e desdobramento, 
necessitando, por conseguinte de planos de intervenções cada vez mais adequadas as suas demandas. Vale salientar que aqui, território é entendido não apenas em sua localidade geográfica, mas como menciona Santos (2001, p.96), é "base do trabalho, de residência, das trocas materiais e espirituais e da vida, sobre as quais ele influi", tratando-se assim de um espaço permeado por questões subjetivas, estigmas e valores sociais e políticos, os quais culminam em construções históricas e que exerce influência sobre sujeitos que ali estão.

\subsection{O PLANEJAMENTO MATRICIAL E O ACOMPANHA- MENTO PROFISSIONAL}

Esta categoria investiga 0 movimento de desconhecimento, de alguns profissionais envolvidos, em relação à compreensão da prática. Trazendo também outros pontos como ausência de documentos para acompanhamento de matriciamento e falta de um projeto para implantação de matriciamento.

Os achados permitem evidenciar a redução da saúde mental ao transtorno, e a transposição de atividades institucionais ao coordenador do CAPS ॥ (também coordenador de saúde mental) que acaba tornando-se 0 único referencial em saúde mental do município. Ao serem questionados acerca da articulação entre o CAPS e outros dispositivos de saúde mental, e sobre o preenchimento de algum documento para 0 acompanhamento do matriciamento os profissionais expressam:

Aqui, é porque aqui a gente fica mais voltado pra álcool e drogas, a parte mental mesmo [...] seria lá com o pessoal mesmo do CAPS Flores. (Ricardo-CAPS-ad)

Aí eu também não sei informar, seria essa parte junto com o programa que se houver ela deve estar fazendo. Aqui assim eu não vejo, mas eu acredito que lá da parte do coordenador de saúde mental deve haver. (Otávio-Atenção Básica)

0 Ministério da Saúde (2005) preconiza que todo problema de saúde está implicado a saúde mental e que a saúde mental, por sua vez, estará sempre imersa na produção de saúde. Desta forma tornase equívoco colocar saúde mental como sinônimo de patologias instauradas, e delegar apenas ao CAPS a assistência a essa demanda. Uma vez, que a Atenção Básica, por meio da USF está diretamente ligada a este processo de cuidado e de matriciamento. Para Campos e Domitti (2007), essa fragmentação no trabalho, seja por organizações ou profissionais, configura-se como um obstáculo estrutural ao matriciamento, em que as instituições tendem a organizar-se de forma que foge do sentido de produção compartilhada, corresponsbilização e cogestão. Aproximando-se assim de um fazer que se caracteriza por atuações isoladas, que desconhecem o funcionamento dos demais dispositivos de saúde.

Em outro relato foi possível observar que não há documento específico, o qual possa ser preenchido para 0 acompanhamento dos casos em territórios que são matriciados, como representado nas falas:

De documentos é? Fica o enca-
minhamento, ne ... é encaminha-
mento por via de transferência do
usuário [...] e o documento que
nós temos é o que a gente faz o
Matriciamento, onde nós faze-
mos as capacitações, com eles,
e temos atas que foram feitas e
realizadas tudo. Não tem uma do-
cumentação um ofício, de controle
de Matriciamento. (Raquel-CAPS
II).
Não, não tem. Foi uma proposta
dos residentes da multiprofissio-
nal, que eles trouxeram, e no caso
a gente orienta que os pacientes
que sejam encaminhados [...] a
necessidade de fazer um acom-
panhamento no CAPS, seja feito
em três vias. (Regina-Atenção
Básica).

É possível observar que este processo de acompanhamento de matriciamento acontece mediante encaminhamentos ou atas de reuniões, reforçando um sistema burocrático de referenciação. Vale ressaltar que a cristalização nesses em tais sistemas de encaminhamentos, com guias de referência e contrarreferência é algo que 0 apoio matricial vem 
justamente tentar amenizar, pois considera-se que tais práticas tradicionais acabam produzindo em grande parte uma desresponsabilização na produção de saúde (FIGUEIRED0, 2006).

Os relatos apontam para a ausência de um projeto oficial, acerca da implantação do matriciamento, como demonstra as falas seguintes:

Não existe, certo. (Talita-Atenção Básica)

Existe, o projeto. Agora que eu não tenho data, de como é que vai ser, quando é que vai ser. (Regina-Atenção Básica).

0 Ministério da Saúde expõe que onde houver CAPS ou outros dispositivos de atenção à saúde mental, estas equipes devem oferecer apoio matricial à atenção básica, mediante encontros semanais, e visitas de urgência, caso haja necessidade (BRASIL, 2015). No contexto do município pesquisado, é possível observar que a afirmação dos profissionais acerca de um projeto matricial está mais voltada para um plano ideológico que propriamente escrito.

\subsection{O MATRICIAMENTO NA RELAÇÃO ENTRE A ATEN- ÇÃO BÁSICA E SERVIÇO DE SAÚDE MENTAL}

Esta categoria engloba a aglomeração de discursos que referenciam a assistência dos serviços de saúde, evidenciando que para os profissionais apenas o Núcleo de Apoio a Saúde da Família (NASF) é referência em matriciamento, que para os envolvidos da pesquisa os papéis do matriciamento $\mathrm{e}$ da intersetorialidade confudem-se, e o contato entre serviços de saúde mental e a atenção básica acontece de forma pontual.

A sistemática de matriciamento, citada pelos profissionais, está sempre em relação ao (NASF), como aqueles que a realizam. Havendo também discursos que confundem matriciamento e intersetorialidade, como se pode observar abaixo:

A gente trabalha com matriciamento dentro da Atenção Básica em relação com o NASF [...] Aí 0 matriciamento do CAPS, não é bem um matriciamento, é uma intersetorialidade. (Jorge-Atenção Básica).

Essas ações em saúde mental são realizadas pelas unidades básicas de saúde, e as unidades que também tem NASF, elas contam com esse apoio, que são de equipes multiprofissionais. (Jorge-Atenção Básica).

Assim como o CAPS, uma das atribuições do NASF trata-se do apoio matricial, entretanto a presença de um dispositivo que realiza matriciamento não exclui a possibilidade do outro atuar neste sentido também. 0 NASF trata-se de uma equipe multidisciplinar, a qual oferece apoio a USF, com o objetivo de ampliar a resolubilidade e maximizar suas ações no território. Conforme o Ministério da Saúde (2010), os NASF's trabalham junto à USF, construindo um trabalho que visa aumentar a qualidade do cuidado, desenvolver atividades de acompanhamento e monitoramento em médio e longo prazo das demandas, e por diversos enfoques. Desta forma, o NASF possui um trabalho voltado para a população e ao agir com as equipes de USF atuam na prevenção e promoção de saúde.

0 matriciamento não deve ser confundido com ações intersetoriais, uma vez que 0 apoio matricial conforme Campos e Domitti (2007), trata de uma proposta interventiva, um arranjo organizacional em que equipes de apoio trabalham com uma equipe de referência de modo que venha concretizar proposições como integralidade, intersetorialidade, clínica ampliada e territorialidade, no cuidado. Enquanto que a intersetorialidade configura-se como um movimento de atenção, que procura unir vários setores de trabalho. 0 sentido de intersetorialidade nasce da compreensão de que a produção de saúde se faz mediante a articulação de diversos setores, possibilitando uma visão mais ampla de homem. Vale salientar que este se trata, sobretudo, de um processo dinâmico. Ao discorrer acerca da intersetorialidade, Bernardi et al. (2010) apontam que ela está pautada na transdisciplinaridade e busca efeitos que venham harmonizar as ações das instituições, de modo que 
haja uma potencialização nos resultados, tais quais não se conseguiria com a mera união de setores.

0 surgimento da categoria matriciamento na relação entre Atenção Básica e serviços de saúde mental, trata-se da comunicação entre os CAPS's e Atenção Básica, que acontece predominantemente por meio de reuniões e fóruns explicativos, ou em situações de crise, em que o CAPS é acionado pela USF. Todavia, este contato não se estende em uma ação que possa ser considerada um matriciamento, uma vez que se configuram em contatos pontuais, não havendo encontros regulares e momentos para discussão de estudos de caso. Como se observa nas falas a seguir:

Mas sempre que a gente necessita, a gente recorre ao CAPS, 0 CAPS também recorre a gente [...] diante de uma necessidade, por exemplo, de uma visita domiciliar de uma pessoa em surto, a gente recorre ao CAPS e o CAPS faz. (Jorge-Atenção Básica).

A gente tem um link muito bom com o pessoal do CAPS [...] Então a gente tem esse link de abertura, de conversa [...] o que tá faltando talvez seja a gente participar da discussão de casos, entre Atenção Básica e CAPS. (Regina-Atenção Básica).

Como uma ferramenta de transformação clínica e social, o apoio matricial pode ser acionado em situações em que a equipe de referência encontra dificuldades em suas relações pessoais ou dúvidas para condução de casos, podendo haver encontros previamente marcados, e visitas de urgência. Ele ainda pode participar de grupos de intervenção psicossocial.

A discussão de casos é uma das ferramentas do matriciamento e pode ser viabilizada durante a interconsulta, que se caracteriza por uma construção colaborativa entre profissionais de áreas distintas, seja para discussão de casos, ou para intervenções como consultas conjuntas e visitas domiciliares (BRASIL, 2011). Nesta discussão, os profissionais dispõem de um momento para compartilharem suas compreensões acerca de um caso, bem como as inquietações e dúvidas.

Essa estratégia de discussão de casos desenvolve a possibilidade para que uma clínica e os desafios de uma prática sejam discutidos por diversas perspectivas, e inclinem-se a interdisciplinaridade (BRASIL, 2011), tornando-a assim mais rica e abrangente, e permitindo a construção conjunta de um Projeto Terapêutico Singular (PTS), que viabiliza uma assistência que foge do tão comum generalismo médico, considerando as singularidades ali existentes, como suas limitações, vulnerabilidades, e potencialidades, e a realização de intervenções em longo prazo e não apenas em crises.

Vale salientar, no que diz respeito à atuação do psicólogo; a discussão de casos configura-se como uma linha tênue, e por vezes pode configurarse como um obstáculo ético. A psicologia tem sua prática embasada pelo sigilo ético que o profissional oferece aos usuários, entretanto, conforme Campos (2003), isto pode complicar-se devido a utilização de um único prontuário para todos os profissionais, e as informações que são compartilhadas durante as discussões, exigindo cautela dos profissionais para lidar com essas questões.

\subsection{SENTIDO DE MATRICIAMENTO}

Esta categoria analítica revela 0 sentido sobre as concepções acerca do matriciamento, demonstrando que de modo geral os profissionais possuem pouco conhecimento do que envolve a prática. Entretanto, enquanto alguns profissionais desprendem de informações apenas superficiais, onde não há propriedade acerca desta prática:

Esse termo ele é novo pra mim [...] por que assim eu não entendia muito quando dizia matriciamento disso, matriciamento daquilo [...], mas eu entendi que seria 0 apoio entre instituições, a interação entre instituições. (Ricardo-CAPS-ad) 
Outros profissionais apresentam maior entendimento sobre a prática e possuem informações relevantes:

Seria a programação né, do trabalho que vem a ser realizado, é [...] voltado pra o paciente de saúde mental, mas não de forma pontual, não só por uma unidade, não só por o posto [...] Seria todo 0 apoio que ele recebe a nível domiciliar, a nível de sociedade, enquanto inserido na sociedade. (Otávio-Atenção Básica)

A compreensão dos profissionais acerca da proposta do matriciamento é de fundamental importância para a construção de uma prática inovadora, que enxerga 0 sujeito em sua integralidade e propõe intervenções que vão além do modelo clássico de assistência em saúde e direciona-se à humanização no cuidado. 0 matriciamento configurase como uma estratégia que valoriza o sujeito em seu contexto, e enquanto protagonista do seu cuidado. "Tornar 0 território um princípio organizador das práticas de cuidado é um processo ético além de ser um princípio técnico, sobretudo nas políticas de Saúde Mental e Atenção Básica" (LEMKE; SILVA 2013, p. 9). Percebe-se que assim há um caminho no sentindo da desinstitucionalização, um processo complexo, que não pode ser considerado meramente a transposição de um lócus, pois se trata primordialmente de uma mudança de paradigmas. Configura-se como um contrato social, o qual jamais deve ser reduzido a desospitalização.

Desta forma, mais que "um apoio entre instituições", a atividade matricial constitui-se como um fazer longitudinal, que se inscreve mediante a interdisciplinaridade e a visão integral de homem, e caminha para uma prática que amplia o sentido de saúde e entende que uma prática deve ser transformada a fim de viabilizar o rompimento com os muros do instituídos. Conforme Nicácio e Campos (2004), este modo de atenção psicossocial substitutivo ao modelo asilar, exige mudanças que vão além das transformações estruturais, e que caminham no sentido da construção de novos arranjos relacionais entre usuário e instituição, e na forma como se faz saúde mental. Trata-se de um fazer em que deve haver um esforço para que o sujeito possa estar em condição de reinserção social, usufruindo de seus direitos enquanto cidadão.

Neste incurso, é de grande pertinência a associação do matriciamento com a prática do psicólogo, uma vez que há uma visão diferenciada para os processos de classificação diagnóstica, que pode ser representada quando Campos (2003), coloca que apesar de 0 agrupamento de sintomas resultarem em estruturas diagnósticas similares, uma mesma patologia pode se dar de forma diferente, uma vez que mesmo diante de evidências semelhantes, elas estão perpassadas por variáveis contextuais, históricas e subjetivas que as tornam singulares, 0 que vem a demandar do serviço de saúde plasticidade para dar conta destas nuances.

\section{CONCLUSÃO}

0 matriciamento, assim como qualquer prática, pode confrontar-se com diversos obstáculos para sua concretização. Especificamente, e sobre uma ótica daqueles profissionais que estão envolvidos com a gestão, é possível perceber que diversas varáveis atuam neste sentido. Entre elas pode-se mencionar a rotatividade dos funcionários; 0 escasso investimento financeiro na saúde mental; 0 modelo curativista em saúde, que ainda se faz presente em algumas atuações e as práticas resistentes aos novos conceitos e formas de atuar que o SUS e a Reforma Psiquiátrica propõem. Nestes dois últimos casos, é possivvel inferir, que há necessidade de intervenções e olhares atentos à formação profissional e pessoal dos profissionais, situação inclusive, que o psicólogo pode vir a contribuir de forma significativa.

A forma com que 0 acolhimento tem sido realizado pelas ESF's, também se distancia da sua real proposta, sendo assim mais uma dificuldade. Uma vez que tanto o SUS, como o matriciamento pressupõe 
acolhimento como algo processual e não pontual. Neste sentido, a psicologia pode auxiliar e oferecer subsídios neste processo, à medida que entende 0 acolhimento e 0 vínculo, como estreitamente ligados a questões subjetivas, podendo também ajudar a lidar com o obstáculo de práticas resistentes, pois incorpora novas noções de cuidados, recriando os modos de intervenção.

Mediante os dados coletados também é possível inferir que a implantação de matriciamento trata-se de uma prática que acaba por ficar mais no plano ideológico que propriamente documentada, fato que talvez também venha dificultar a concretização desta ação. Outro fato importante é que o fazer matricial não raro é associado apenas ao NASF, sendo este compromisso do CAPS com 0 território enfraquecido, pois acontece em situações pontuais de crise, e necessita de intervenções que as amplie.

Apesar das dificuldades observadas, 0 município possui algumas potencialidades, que podem ajudar ao matriciamento, como a realização do mapeamento da região, para um conhecimento melhor das microáreas; a comunicação que existe entre CAPS e Atenção Básica por meio de reuniões, bem como a abertura que há entre os dois dispositivos para solicitação de encontros e algumas atividades direcionadas a intersetorialidade em saúde mental. Estes fatores podem ser fortalecidos e funcionar como via de acesso a uma ampliação nas práticas.

Esta pesquisa também evidenciou a necessidade de uma sensibilização profissional acerca do matriciamento e sua importância, pois apesar da maior parte dos sujeitos possuírem informações e uma compreensão acerca do que isto se trata, está ainda não se configura como uma prática efetiva dos CAPS's.

\section{REFERÊNCIAS}

AMARANTE, P. Loucos pela vida: a trajetória da reforma psiquiátrica no Brasil. Rio de Janeiro: Fiocruz, 1995.
AYRES, J. R. de C. M. Sujeito, intersubjetividade e práticas de saúde. Ciência e Saúde Coletiva, São Paulo, v. 6, n. 1, p. 171-184, 2001. Disponível em: $<$ http://www.scielo.br/pdf/csc/v6n1/7025.pdf>. Acesso em: 18 jun. 2015.

BARDIN, L. Análise de conteúdo. Edições 70: Lisboa, 2006.

BERNARDI, A. P.; D' ANDRÉA, A.I.R.; ZAMPIROLO, D.A.; PERINI, S.; CALVO, M.C.M. Intersetorialidade um desafio de gestão em Saúde Pública. Saúde \& Transformação Social, Florianópolis. v. 1, n. 1, p. 137-142, 2010. Disponível em: <http://incubadora. periodicos.ufsc.br/index.php/saudeetransformacao/ article/viewFile/408/463 > . Acesso em: 08 set. 2015.

BRASIL. Conselho Nacional de Saúde. Resolução CNS $\mathbf{n}^{\mathbf{0}} \mathbf{4 6 6}$ de 12 de Dezembro de 2012. Aprova diretrizes e normas regulamentadoras de pesquisa envolvendo seres humanos. Disponível em: <http://www.conselho. saude.gov.br/resolucoes/2012/Res0466.pdf>. Acesso em: 19 abri. 2015.

BRASIL. Lei n. ${ }^{0}$ 8.080, de 19 de Setembro de 1990. Dispõe sobre as condições para promoção, proteção e recuperação da saúde, a organização e o funcionamento dos serviços correspondentes e da outras providências. Brasília, DF, 19 de set. de 1990. Disponível em: <http://www.planalto.gov.br/ccivil_03/ leis/L8080.htm> Acesso em: 32 out. 2016.

BRASIL. Ministério da Saúde. Portaria $\mathbf{n}^{\mathbf{0}} \mathbf{3 . 0 8 9}$, de 23 de dezembro de 2011. Dispõe, no âmbito da Rede de Atenção Psicossocial, sobre 0 financiamento dos Centros de Atenção Psicossocial (CAPS). Disponível em: $\quad<$ http://bvsms.saude.gov.br/bvs/saudelegis/ gm/2011/prt3089_23_12_2011_rep.html>. Acesso em: 29 out. 2015.

BRASIL. Ministério da Saúde. Guia prático de matriciamento em saúde mental. Ministério da Saúde: Centro de Estudo e Pesquisa em Saúde Coletiva, Distrito Federal, Brasília, p. 236, 2011. Disponível em: $<$ http://bvsms.saude.gov.br/bvs/publicacoes/guia_ pratico_matriciamento_saudemental.pdf>. Acesso em: 15 mai. 2015. 
BRASIL. Ministério da Saúde. Política Nacional de Humanização. Atenção Básica. Caderno HumanizaSUS, Distrito Federal, Brasília, v.2. p. 256, 2010. Disponível em: <http://bvsms.saude.gov.br/ bvs/publicacoes/cadernos_humanizasus_atencao_ basica.pdf>. Acesso em: 15 mai. 2015.

BRASIL. Ministério da Saúde. Reforma Psiquiátrica e política de Saúde Mental no Brasil. Conferência Regional de Reforma dos Serviços de Saúde Mental: 15 anos depois de Caracas. Brasília, nov. 2005. Disponível em: <http://bvsms.saude.gov.br/bvs/publicacoes/ Relatori015_anos_Caracas.pdf $>$. Acesso em: 9 abri. 2015.

BRASIL. Ministério da Saúde. Saúde Mental e Atenção Básica: 0 vínculo e 0 diálogo necessários. Brasília, DF, s.d. Disponivel em: <https://www.nescon.medicina. ufmg.br/biblioteca/imagem/1734.pdf>. Acesso em: 28 jun. 2015.

CAMPOS, G. W. de S. Saúde Paidéia. São Paulo: Hucitec, 2003.

CAMPOS, G. W. S.; DOMITTI, A. C. Apoio matricial e equipe de referência: uma metodologia para gestão do trabalho interdisciplinar em saúde. Caderno de Saúde Pública, Rio de Janeiro, v. 23, n. 2, p. 399-407, fev. 2007. Disponível em: <http://www.scielo.br/pdf/csp/ v23n2/16.pdf >. Acesso em: 6 maio 2015.

CARNEIRO, H.F. Notas de aula da disciplina de Saúde Mental. Garanhuns: Universidade de Pernambuco, Campus Garanhuns, ago.2014.

CUNHA, G. T.; CAMPOS, G. W. de S. Apoio Matricial e Atenção Primária em Saúde. Saúde e Sociedade, São Paulo, v. 20, n. 4, p. 961-970, 2011. Disponível em: <http://www.scielo.br/pdf/sausoc/v20n4/13.pdf>. Acesso em: 30 ago. 2015.

DIAS, M.T.G. A reforma psiquiátrica brasileira e os direitos dos portadores de transtorno mental: uma análise a partir do serviço residencial terapêutico morada São Pedro. 2007. 292f. Tese (Doutorado) Pontifícia Universidade Católica do Rio Grande do Sul, Porto Alegre, 2007.
DIMENSTEIN, M.; MACED0, J. P. Formação em Psicologia: requisitos para atuação na atenção primária e psicossocial. Psicologia Ciência e Profissão, Brasília, v. 32, p. 232-245, 2012. Disponível em: $<$ http://www.redalyc.org/pdf/2820/282024795016. pdf $>$. Acesso em: 18 set. 2015.

FERR0, L. P; SILVA, E. C. da.; ZIMMERMANN, A.B.; CASTANHARO, R.C.T.; OLIVEIRA, F.R.L.de. Interdisciplinaridade e Intersetorialidade na Estratégia Saúde da Família e no Núcleo de Apoio à Saúde da Família: potencialidades e desafíos. 0 Mundo da Saúde, São Paulo, v. 8, n. 2, p. 129-138, 2014. Disponível em: <http://bvsms.saude.gov.br/bvs/ artigos/mundo_saude/interdisciplinariedade_ intersetorialidade_estrategia_saude_familia.pdf>. Acesso em: 23 out. 2016.

\section{FIGUEIRED0, M. D. Saúde Mental na Atenção}

Básica: um estudo hermenêutico narrativo sobre 0 apoio matricial na rede SUS-Campinas (SP). 2006. 134f. Dissertação (Mestre em Saúde Coletiva) Universidade Estadual de Campinas, Campinas, 2006.

LEMKE, R.A.; SILVA, R.A. N. da. Itinerários de construção de uma lógica territorial do cuidado. Psicologia \& Sociedade, v. 25, n. spe. 2, p. 9-20, 2013. Disponível em: <http://www.ufrgs.br/seerpsicsoc/ojs2/index. php/seerpsicsoc/article/view/3685/2302>. Acesso em: 13 jun. 2015.

LUZIO, A.M.; L'ABBATE, S. A atenção em Saúde Mental em municípios de pequeno e médio portes: ressonâncias da reforma psiquiátrica. Ciência e Saúde Coletiva, São Paulo, v. 14, n. 1, p. 105-116, 2009. Disponível em: <http://www.scielo.br/pdf/csc/ v14n1/a16v14n1.pdf > . Acesso em: 17 mar. 2015.

MATUMOTO, S. 0 acolhimento: um estudo sobre seus componentes e sua produção em uma unidade na rede básica de serviços de saúde. 1996. 219f. Dissertação (Mestre em Enfermagem de Saúde Pública) Universidade de São Paulo, Ribeirão Preto, 1998. 
MELO, M. C. B. de.; ROCHA, T.T.de.A.; LIMA, N.N.de.; ANDRADE, A.R.de. Financiamento público e modelo de atenção à saúde no estado de Pernambuco nos anos de 2008 a 2012. Saúde e Pesquisa, Maringá, v. 7, n. 3, p. 495-501, 2014. Disponível em: < http:// periodicos.unicesumar.edu.br/index.php/saudpesq/ article/viewFile/3420/2502> Acesso em: 23 out. 2016.

NICÁCIO, F.; CAMPOS, G. W. S. A complexidade da atenção às situações de crise - contribuições da desinstitucionalização para a invenção de práticas inovadoras em saúde mental. Revista Terapia Ocupacional, São Paulo, v. 15, n. 2 p. 71-81, 2004. Disponível em: <http://www.revistas.usp.br/rto/article/ view/13942/15760 >. Acesso em: 2 abr. 2014.

PEDROS0, R.T.; VIEIRA, M.E.M. Humanização das práticas de saúde: transversalizar em defesa da vida. Interface-Comunicação, Saúde e Educação, São Paulo, v. 13, n. 1, p.695-700, 2009. Disponível em:<http://www.scielo.br/pdf/icse/v13s1/a20v13s1. pdf $>$ Acesso em: 23 out. 2016.

PIETROLUONGO, A. P. da C.; RESENDE, T. I. M. de. Visita Domiciliar em Saúde Mental - 0 Papel do Psicólogo em Questão. Psicologia Ciência e Profissão, Brasília, v. 27, n. 1, p. 22-31, 2007. Disponível em: <http://pepsic. bvsalud.org/pdf/pcp/v27n1/v27n1a03.pdf >. Acesso em: 27 set. 2015.

\section{RABELO, J. B. A intersetorialidade da política de} saúde e os reflexos no desenvolvimento das ações de saúde mental. Recife: Prefeitura Municipal do Recife, [19--.] Disponível em: <http://www.xiconlab.eventos. dype.com.br/resources/anais/3/1306555663_ ARQUIVO_TextoCONLAB-Josines.pdf>. Acesso em: 15 out. 2015.

SANTANA, F. R. NAKATANI, A. Y. K.; FREITAS, R. A. M.DA. M.; SOUZA, A.C. S.; BACHION, M. M. Integralidade do cuidado: concepções e práticas de docentes de graduação em enfermagem do Estado de Goiás. Ciência e Saúde Coletiva, Goiás, v. 15, n. 1, p. 1653-1664, 2010. Disponível em: <http://www. scielosp.org/pdf/csc/v15s1/077.pdf> Acesso em: 19 out. 2015.

SANTOS, G. V. dos. Formação interdisciplinar em educação física: política para promoção da saúde e QV. Saúde e Pesquisa, v. 8, ed. especial, p. 123-138, 2015.

SANTOS, M. 0 território do dinheiro e da fragmentação. In: SANTOS, M. Por uma outra globalização: do pensamento único a consciência universal. 7. ed. Rio de Janeiro: Record, 2001. p.79-116.

SCHIMITH, M. D.; LIMA, M. A. D. S. Acolhimento e vínculo em uma equipe do Programa da Saúde da Família. Caderno de Saúde Pública, Rio de Janeiro, v. 20, n. 6, p. 1487-1494, nov./dez. 2004. Disponível em: <http://www.scielosp.org/pdf/csp/v20n6/05.pdf >. Acesso em: 11 mar. 2015.

TAVARES, C. M. de M. A educação permanente da equipe de enfermagem para 0 cuidado nos serviços de saúde mental. Texto Contexto-Enfermagem, Florianópolis, v. 15 n. 2, p 287-295, abr./jun. 2006. Disponível em: <http://www.scielo.br/pdf/tce/v15n2/ a12v15n2.pdf >. Acesso em: 9 out. 2015.

Recebido em: 29 de junho de 2016 Aceito em: 01 de novembro de 2016 